\title{
Prognostic value of anti-dsDNA in SLE
}

\author{
A. J. G. SWAAK,${ }^{1} \mathrm{~J}$. GROENWOLD ${ }^{2} \mathrm{~L}$. A. AARDEN ${ }^{2} \mathrm{~L}$. W. STATIUS VAN \\ EPS,${ }^{3}$ AND T. E. W. FELTKAMP ${ }^{2}$
}

From the ${ }^{1}$ Jan van Breemen Instituut, Centre for Rheumatic Diseases, Amsterdam, the ${ }^{2}$ Department of Autoimmune Diseases, Central Laboratory of the Netherlands Red Cross Blood Transfusion Service and Laboratory for Experimental and Clinical Immunology of the University of Amsterdam, and the ${ }^{3}$ Department of Internal Medicine, Slotervaart Hospital, Amsterdam, The Netherlands

SUMMARY In a prospective longitudinal study 130 patients with systemic lupus erythematosus (SLE) were studied at least monthly for a relationship between the anti-dsDNA levels and disease activity. We observed 13 patients who developed 15 periods of exacerbations of their disease. All 15 exacerbations were preceded by a continuous increase of the anti-dsDNA levels. In 13 of the 15 exacerbations studied the exacerbation was preceded by an increase of anti-dsDNA with a doubling time (T2) of less than 6 weeks; in 4 of the 5 other exacerbations the T2 was less than 10 weeks. Four other patients with an increase of the anti-dsDNA levels showed no exacerbation. In these 4 patients the T2 was larger than 10 weeks. The other 113 patients did not show an increase of anti-dsDNA over the 2 years of monitoring and showed no signs of serious disease activity (no major symptoms). These observations suggest that an SLE patient who is followed up frequently and who shows a continuous increase of anti-dsDNA with a T2 shorter than 10 weeks is bound to develop an exacerbation.

With the proper assay systems the diagnostic value of antibodies to double-stranded (ds)DNA seems to be beyond doubt. ${ }^{1}$ Antibodies to dsDNA are found in high frequency in the serum of patients with active systemic lupus erythematosus ${ }^{2}$ (SLE) but not in the serum of normal persons and patients with a variety of other autoimmune diseases, such as discoid lupus erythematosus, ${ }^{3}$ chronic hepatitis, ${ }^{4}$ or rheumatoid arthritis. ${ }^{56} \mathrm{~A}$ more difficult problem is the relation between the anti-dsDNA level and disease activity. Systematic longitudinal studies are scarce and suffer from inadequate quantitation of anti-dsDNA and infrequent serum sampling. This might be the reason why no conclusion has yet emerged about the relation of anti-dsDNA level to disease activity. The only consistent finding is that patients with a persistently high anti-dsDNA level are bound to develop a major flare-up of the disease more frequently than patients with a low level. ${ }^{7}$

Elevated levels of anti-dsDNA, however, may persist for several years before such a flare-up occurs. On treatment of the patient the anti-dsDNA level decreases, and it has been suggested that this might be used to monitor therapy. ${ }^{7-9}$

Accepted for publication 23 July 1981.

Correspondence to Dr A. J. G. Swaak, Dr Daniel Den Hoed Kliniek, Department of Rheumatology, Groene Hilledijk 301, 3075 EA Rotterdam, The Netherlands.
By thorough quantitation of anti-dsDNA and frequent serum sampling one can find a strict relationship between anti-dsDNA levels and disease activity. ${ }^{10}{ }^{11}$ In a group of 43 SLE patients major symptoms of disease occurred only during a rapid decrease of the anti-dsDNA level. It was suggested

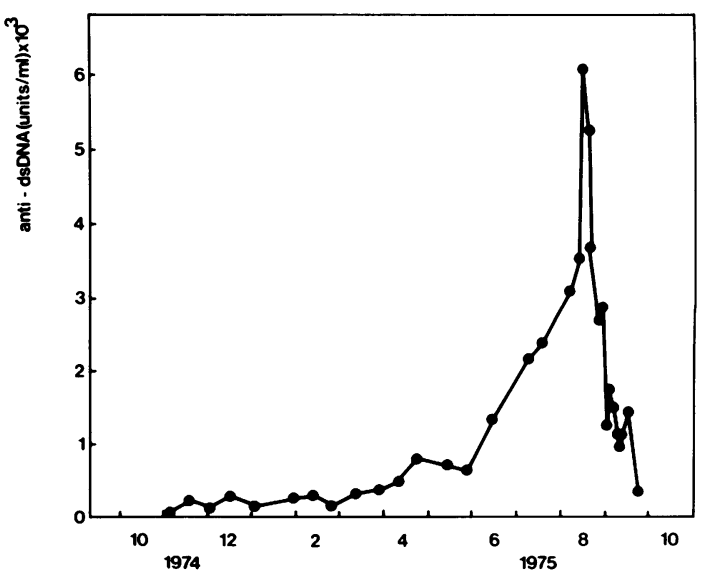

Fig. 1 The anti-dsDNA course of patient A, a 62-year-old female, who developed anaemia at the end of July 1975. A further clinical deterioration took place in August. At the end of August signs of renal involvement developed, and she died on 27 September. 
that the decrease of anti-dsDNA was independent of the start of immunosuppressive or corticosteroid therapy. This may imply a causal relationship between a fall of the anti-dsDNA level and an exacerbation.

A major drawback of that study was its retrospective character. Most patients entered the study at a time at which therapy had already been started. Moreover, the period preceding an exacerbation could not be analysed properly.

We here describe the result of a prospective longitudinal study of 130 SLE patients on the precise relation between anti-dsDNA levels and the occurrence of exacerbations, with emphasis on the period preceding the exacerbation.

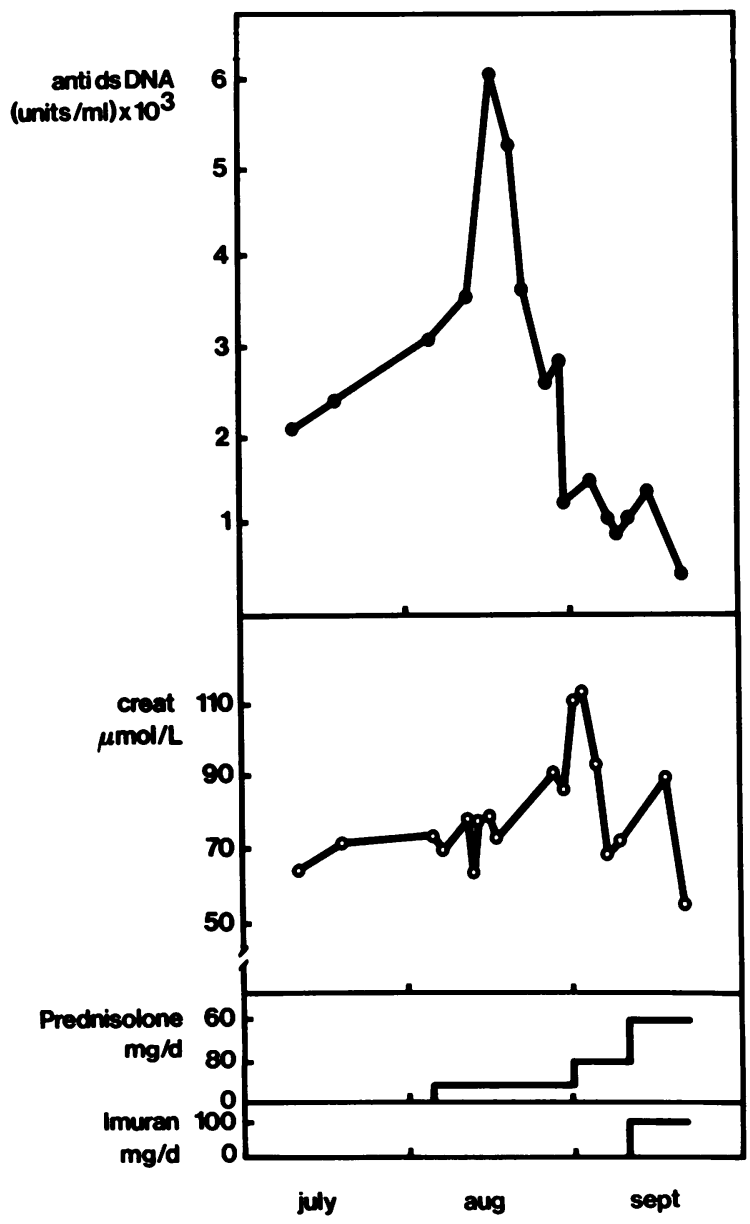

Fig. 2 The anti-dsDNA levels of the same patient as depicted in Fig. 1 in relation to the renal function (creatinine levels).
Table 1 Patients with constant levels of anti-dsDNA

\begin{tabular}{lll}
\hline $\begin{array}{l}\text { Number of } \\
\text { patients }\end{array}$ & $\begin{array}{l}\text { Anti-dsDNA levels } \\
\text { (units/ml) }\end{array}$ & $\begin{array}{l}\text { Mean observation time } \\
\text { (years) }\end{array}$ \\
\hline 56 & $<20$ & $2 \cdot 8$ \\
16 & $20-50$ & 1.9 \\
8 & $50-150$ & 1.6 \\
26 & $>150$ & 1.9 \\
\hline 106 & & \\
\hline
\end{tabular}

\section{Materials and methods}

\section{SELECTION OF PATIENTS}

In 3 clinical centres in the Netherlands-the Department of Internal Medicine of the Slotervaart Hospital (Amsterdam), the Department of Internal Medicine of the Free University Hospital (Amsterdam), and the Department of Rheumatic Diseases of the Daniel Den Hoed Hospital (Rotterdam)-130 patients meeting the preliminary ARA criteria for the diagnosis SLE were routinely screened at 6-week intervals. When the patients had more complaints of disease, the frequency of clinical and serological investigation was increased to, if possible, weekly intervals. Treatment of patients were not guided or influenced by serological data. In a period of about 2 years we recorded 15 exacerbations in 13 patients. All clinical exacerbations were accompanied by a changing level of anti-dsDNA as will be shown below.

\section{LABORATORY METHODS}

Venous blood was collected, and after coagulation and centrifugation the serum was stored at $-20^{\circ} \mathrm{C}$.

Anti-dsDNA was determined in a modified Farr assay, using as antigen ${ }^{3} \mathrm{H}$-labelled circular bacteriophage $\left(\mathrm{PM}_{2}\right)$ DNA with a molecular weight of $5.9 \times$ $10^{6}$. This ${ }^{3} \mathrm{H}$-labelled $\mathrm{PM}_{2}$ DNA was purified according to Espejo and Canelo ${ }^{12}$ and found to be free of ssDNA. ${ }^{13} 50 \mu \mathrm{l}$ serum or dilutions in phosphate buffered saline (PBS) was incubated with $100 \mathrm{ng}{ }^{3} \mathrm{H}$ labelled dsPM $\mathrm{M}_{2}$ DNA. The total amount of antibodies was expressed in units $/ \mathrm{ml}$. One unit is defined as the amount of anti-dsDNA that binds $30 \%$ of $100 \mathrm{ng}$ $\mathrm{PM}_{2}$ DNA under standard conditions. ${ }^{14}$

Table 2 Major exacerbations in 13 SLE patients with changing levels of anti-dsDNA

\begin{tabular}{lc}
\hline Type of exacerbation * & Number of patients \\
\hline Lupus nephritis & 13 \\
Haematological abnormalities & 6 \\
Cardiopulmonary symptoms & 5 \\
Neuromuscular symptoms & 1
\end{tabular}

*Combined types of exacerbation were noted separately. 
Table 3 Clinical symptoms during increasing anti-dsDNA levels

\begin{tabular}{lc}
\hline Symptoms & Number of patients \\
\hline Fatigue, low-grade fever, loss of weight & 11 \\
Skin rash, Raynaud's phenomenon, alopecia & 4 \\
Arthritis, arthralgia, muscle pain, weakness & 8 \\
Proteinuria, cellular casts & 3 \\
\hline
\end{tabular}

\section{DISEASE ACTIVITY}

Clinical activity was recorded by the clinician without knowledge of serological parameters. It was divided into minor and major symptoms, as described by Lightfoot and Hughes ${ }^{15}$ and Swaak et al. ${ }^{11}$ Minor symptoms were those characterised mainly by involvement of the dermato-musculo-skeletal system which could be controlled with an increased dosis of prednisolone of 5 to $15 \mathrm{mg}$. Flare-ups of disease were considered major when there was a combination of the following manifestations: renal impairment, serositis, anaemia ( $\mathrm{Hb}<7 \mathrm{mmol} / \mathrm{l})$, leucocytopenia (white cell count $<4 \times 10^{9} / 1$ ), thrombocytopenia (platelet count $<50 \times 10^{\%} / 1$ ), or neurological and psychiatric symptoms. Deterioration of the renal function was considered to have occurred when urine protein increased to at least $1 \mathrm{~g} /$ day or when, according to analysis of a urinary sediment, leucocytes, red blood cells, or casts appeared, or, when already present abnormally, increased 2-fold, or when a fall of more than $20 \%$ in the glomerular filtration rate (GFR) was recorded.

An increase of urine protein, sediment abnormality, or a fall in GFR were considered significant if they were observed on at least 3 consecutive days. Patients with pre-established renal involvement were considered to be inactive when no alteration took place of the serum creatinine level, proteinuria, the urine sediment, or the blood pressure. An increase in proteinuria, or other signs of a further deterioration of renal function in the absence of other causes unrelated to. SLE, such as pyelonephritis, were indicative of active renal disease.

\section{Results}

PATIENTS WITH A CONSTANT LEVEL OF ANTI-DSDNA

The 130 patients were divided into 2 groups on their anti-dsDNA profiles. The majority (106) of the patients did not show fluctuations of more than a factor of 2 in the anti-dsDNA level in the 2 years of monitoring. Although 50 out of these 106 patients had an elevated level of anti-dsDNA (Table 1) for more than a year, no signs of serious disease (major symptoms) were observed in these 106 patients.
PATIENTS WITH VARYING ANTI-DSDNA

The other group of 24 patients were entirely different. The anti-dsDNA levels in these patients varied in time. Moreover, 15 major exacerbations were observed in 13 of these patients, mainly with manifestations of lupus nephritis (Table 2).

Anti-dsDNA profiles in patients undergoing a major exacerbation were very similar in all 13 patients. At the time of the exacerbation peaking anti-dsDNA levels were observed. A typical example is given in Figs 1 and 2.

In November 1974 patient A, a 62-year-old female, was included in our anti-dsDNA monitoring system. Clinically she had been free of complaints until

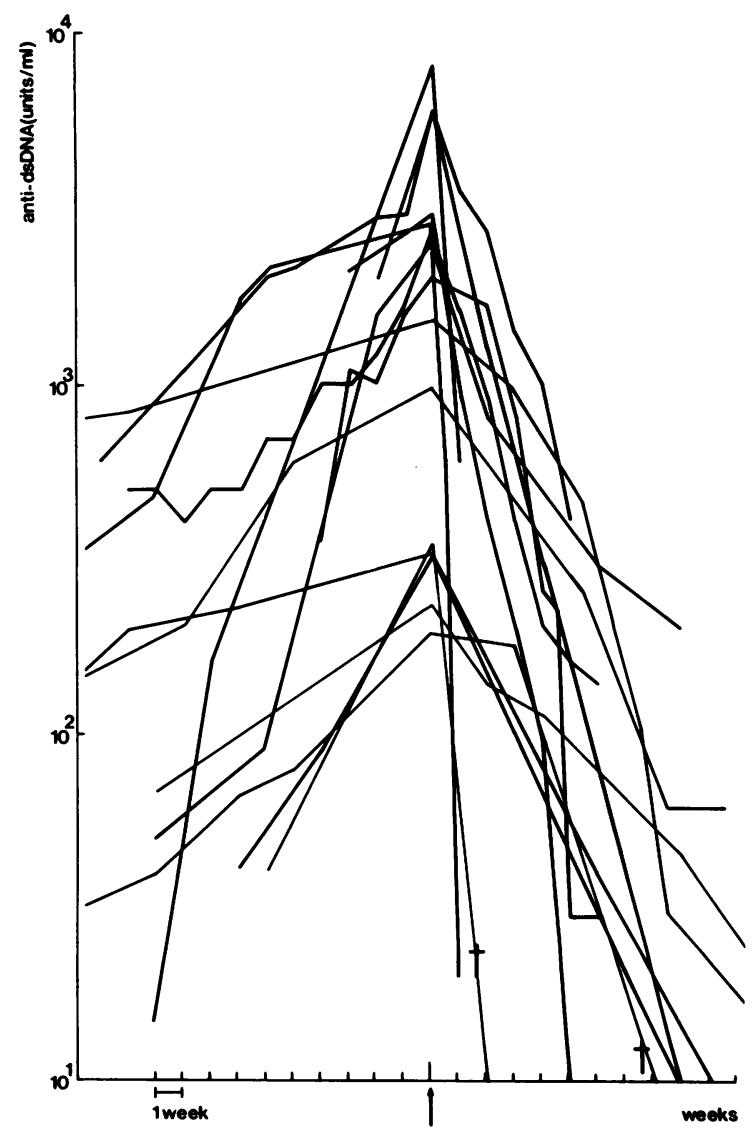

Fig. 3 Patterns of anti-dsDNA of 15 patients who developed a major exacerbation. Only the periods just before and after the exacerbations are shown. At the arrow the highest anti-dsDNA were assembled. This point coincided within a week with the occurrence or presence of the exacerbation (major symptoms). Note that the anti-dsDNA levels are on log scale. It should be noted that a continuous plateau level was never obtained. 


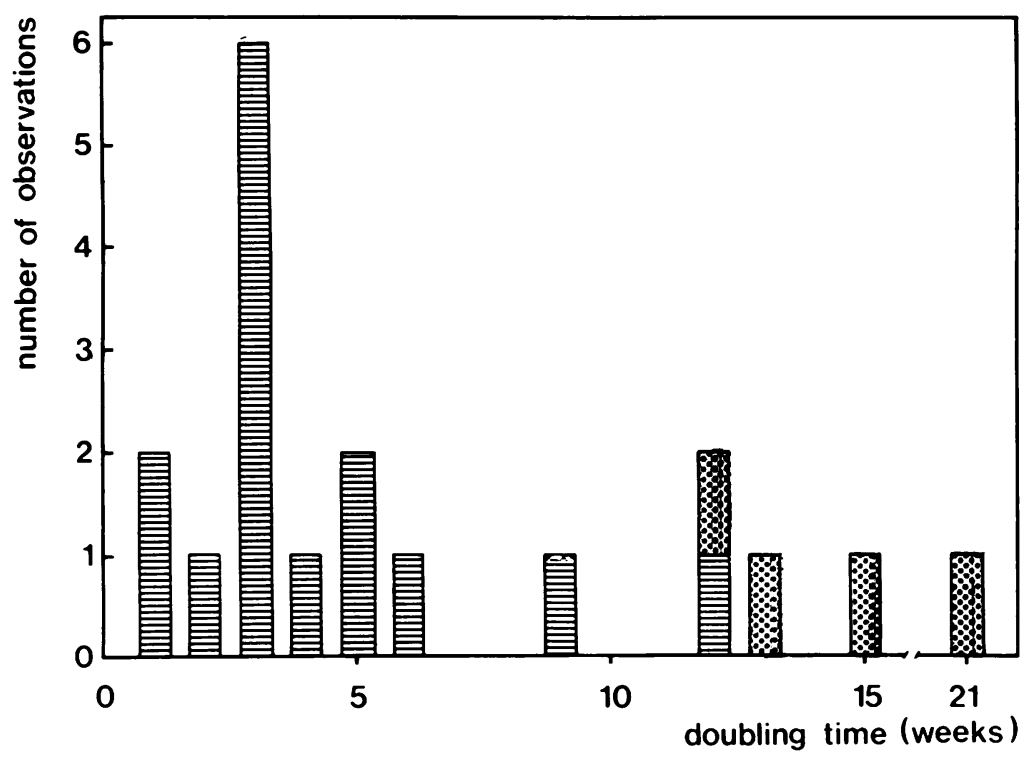

Fig. 4 Doubling time of anti-dsDNA levels. Nineteen periods of increases in the anti-dsDNA levels in 17 patients were analysed. In 15 cases (目) the rising anti-dsDNA levels preceded an exacerbation. The other 4 patients ( exacerbation. All situations where the doubling time was under 10 weeks preceded an exacerbation.

1972. Then she developed periods of arthritis. In 1973 the LE-cell test was found to be positive. In November 1974 no anti-dsDNA was detectable in her serum, but from March 1975 onwards antidsDNA was detected and from then on slowly increased. In this period the patient suffered from polyarthritis, low febrile temperature, and loss of weight. On 2 July 1975 she was admitted to the hospital. There initially all complaints disappeared, but at the end of July the clinical picture changed. Complaints of arthritis, tiredness, and low febrile temperature reappeared. On these grounds treatment with prednisolone (15 mg/day) was started on 3 August. At this time only minor symptoms were present. The haemoglobulin level decreased slowly, and after 18 August values under the $7 \mathrm{mmol} / 1$ level were reached (the lowest value was on 24 August, $5 \mathrm{mmol} / \mathrm{l}$ ). Haemolysis as well as loss of blood were excluded; a sternum aspirate was normal. The peak level of antidsDNA was found on 14 August (6074 units $/ \mathrm{ml}$ ).

After the anaemia a leucocytopenia and thrombocytopenia developed. According to the criteria of disease activity the start of the exacerbation took place on 18 August (anti-dsDNA level at that moment amounted to 5210 units $/ \mathrm{ml}$ ). Signs of deterioration of renal function were detected for the first time on 25 August (anti-dsDNA: 2672 units $/ \mathrm{ml}$ ). A slight but persistent proteinuria (about 1 $\mathrm{g} / 24 \mathrm{~h}$ ) was found; urine analysis showed the presence of erythrocytes, leucocytes, and hyaline cylinders. In the period from 16 to 25 August the creatinine level increased from 72 to $90 \mu \mathrm{mol} / 1$. On
1 September prednisolone was increased to 30 $\mathrm{mg} /$ day. Because of the patient's severe disease activity (deterioration of renal function, anaemia, leucocytopenia, and thrombocytopenia), prednisolone was raised to $60 \mathrm{mg} /$ day and she was started on $75 \mathrm{mg}$ azathioprine. This was followed by improvement, mainly of the renal function; however, the patient died on 27 September (sepsis). Histopathological examination of the kidney showed a focal-local glomerulonephritis.

Such a pattern of rise and fall of anti-dsDNA was found to accompany all 15 exacerbations (Fig. 3). Therefore on the basis of these observations 2 questions are posed. Does a rising anti-dsDNA level herald a major exacerbation? And is the decrease in anti-dsDNA level seen after the onset of the exacerbation the result of therapy, or is it related to the cause of the exacerbation?

RISING ANTI-DSDNA LEVEL HERALDSA MAJOR EXACERBATION

All 15 exacerbations observed in these patients were preceded by an increasing serum anti-dsDNA level (Fig. 3). However, there were 4 other patients with an increase in the anti-dsDNA level who did not show an exacerbation. In these 4 patients the doubling time seemed to be longer than in the other 15 . To evaluate these differences we calculated from each patient the doubling time (T2) of anti-dsDNA based on the mean slope of a semilog plot of anti-dsDNA levels against time. In the 4 cases in which no exacerbation took place the T2 was longer than 10 weeks (Figs 4 


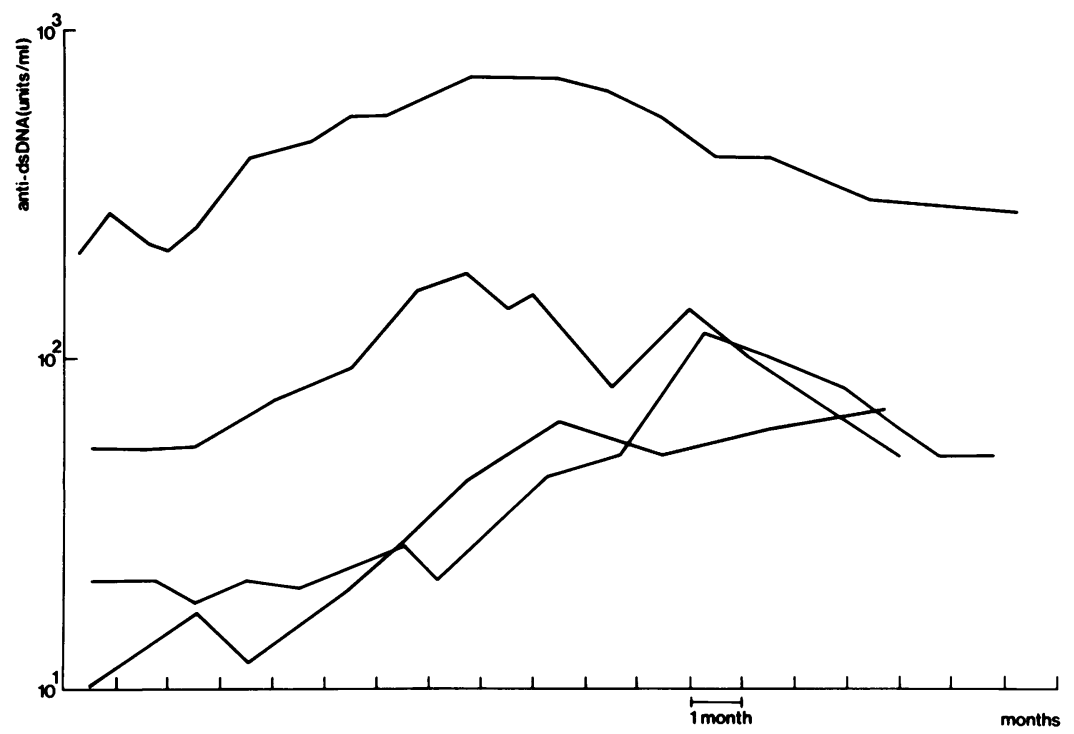

Fig. 5 Patients with a 'slow' increase of anti-dsDNA. The 4 patients with increases of anti-dsDNA with a doubling time longer than 10 weeks. In these patients no exacerbation was observed. Clinically these patients were not different from the 106 patients with stable anti-dsDNA.

and 5). In all cases in which a T2 under 10 weeks was found the increase of anti-dsDNA heralded the exacerbation. The mean increment of anti-dsDNA levels before the exacerbation took place was found to be 80 -fold ( 3 and 570 as extreme values). The average time interval, measured from the time of the lowest positive anti-dsDNA value (15 or more units $/ \mathrm{ml}$ ) till the highest level was reached, was 16 weeks. The longest period was 34 weeks, the shortest 7 weeks.

\section{CLINICAL MANIFESTATIONS DURING THE} PERIOD OF INCREASING ANTI-DSDNA In all 13 patients, showing 15 periods of exacerbation, minor symptoms of disease were observed during the increase of anti-dsDNA (Table 3 ). In 3 cases the development of major symptoms started more or less at the end of this period, as shown in Figs 1 and 2. In the other 12 exacerbations observed major symptoms occurred more in time with the obvious sudden drop in the anti-dsDNA level, as shown below.

DECREASING ANTI-DSDNA IS RELATED TO

THE EXACERBATION

In 20 patients we noted 22 periods of decreasing anti-dsDNA levels. In 14 periods the $T_{2}^{\frac{1}{2}}$ of antidsDNA was 2 weeks or less (Figs 6 and 7). Together with one case in which the $T \frac{1}{2}$ was 6 weeks these were the 15 situations in which a major exacerbation was seen. Patients with a more extended $\mathrm{T}_{2}^{\frac{1}{2}}$ did not develop such exacerbations. As mentioned before, 12 observations showed that the exacerbation started

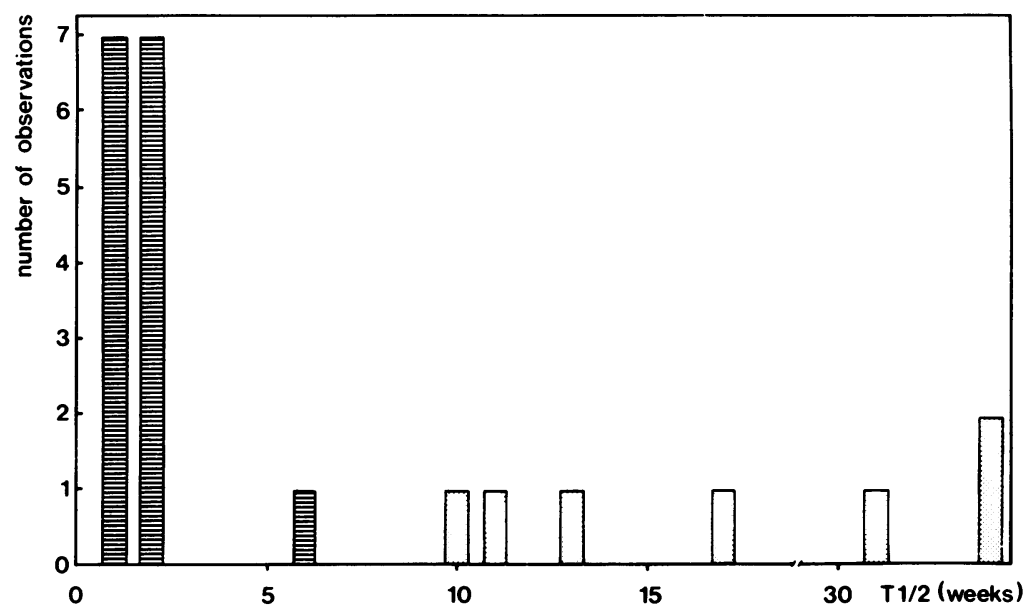

Fig. 6 T $\frac{1}{2}$ of anti-dsDNA levels in the period of the exacerbation. Frequency of 21 periods in which anti-dsDNA levels decreased. In 15 periods (目) major disease activity was found (characterised by a $T_{\frac{1}{2}}^{1}$ shorter than 2 weeks, with one exception of 6 weeks). All other cases developed no exacerbation (因). 


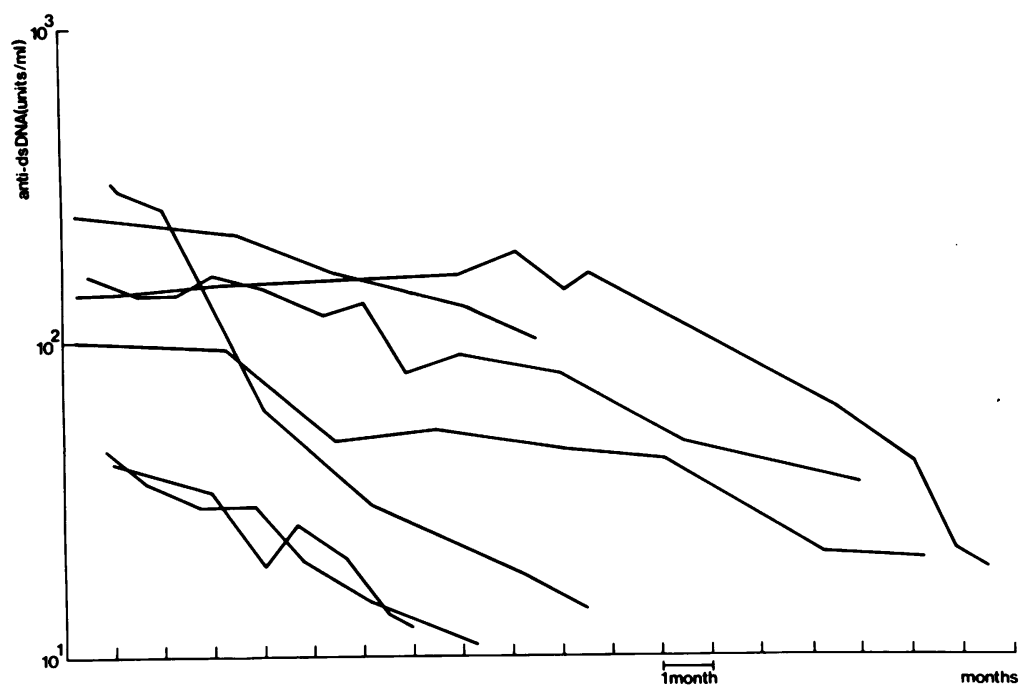

Fig. 7 Patients with a slow decrease of anti-dsDNA levels. Anti-dsDNA levels decreased slowly in 7 patients. On clinical grounds it was impossible to differentiate these patients from the 106 patients with stable anti-dsDNA levels.

Fig. 8 Effect of therapy on anti-dsDNA levels. In patient $B$ signs of renal involvement were diagnosed on 16 July 1976. The period from 3 to 17 July was characterised by decreasing anti-dsDNA levels. High-dose prednisolone was started on 22 July.

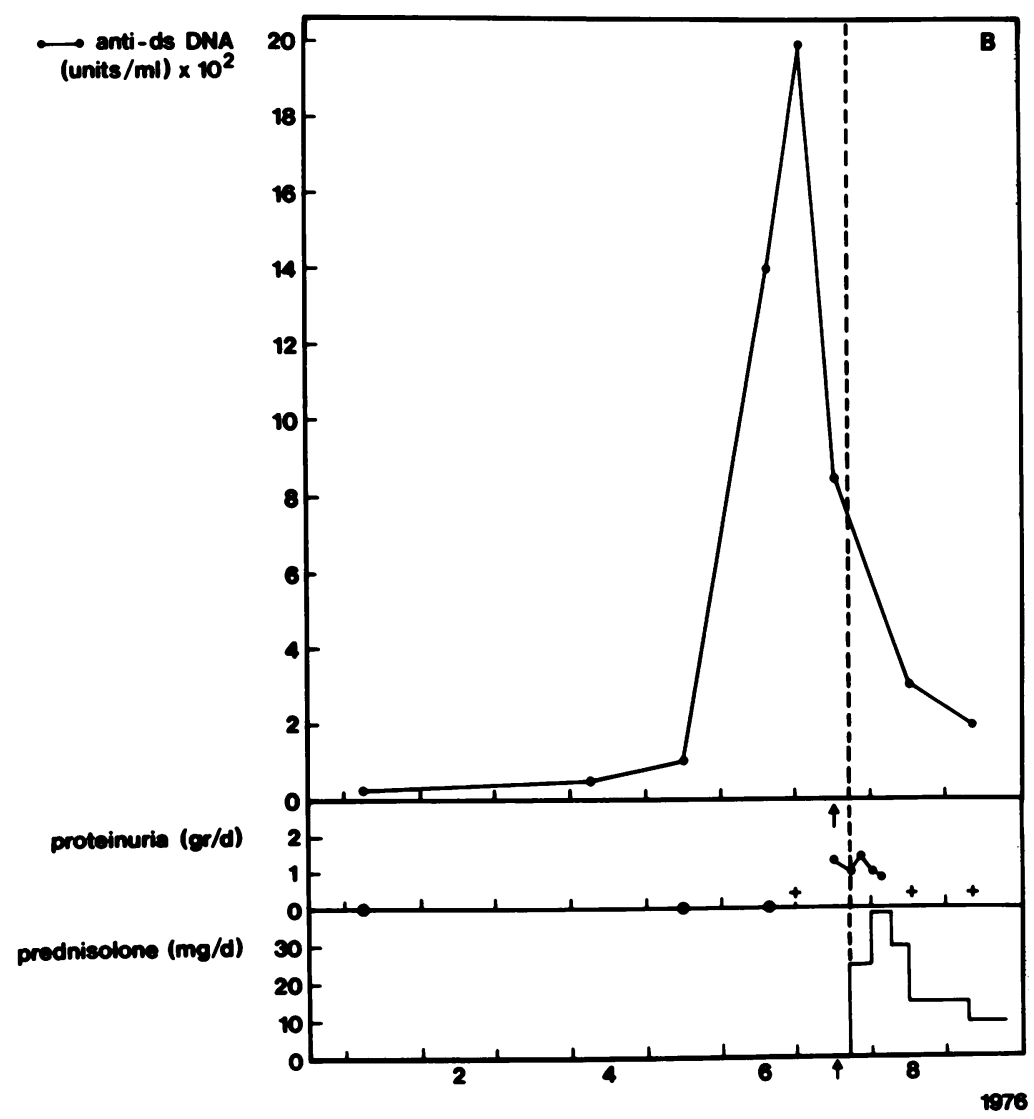




\section{Swaak, Groenwold, Aarden, Statius van Eps, Feltkamp}

after the onset of the decrease of anti-dsDNA. In the other 3 patients major symptoms started while antidsDNA was still increased, but within one week this was followed by a similar fast decrease of anti-dsDNA.

IS THE DECREASE OF ANTI-DSDNA A RESULT OF THERAPY?

In all 15 periods of an exacerbation a rapid decrease of the serum anti-dsDNA level took place. This raises the question whether this decrease is related to the pathogenesis of the lesions or whether it is an epiphenomenon. Therefore, it would be interesting to know whether this decrease is influenced by therapy. Here we encounter a serious problem. Generally, therapy is started the moment an exacerbation becomes manifest. As this is the very same moment when the anti-DNA level starts to fall, this does not allow a conclusion about the mechanism. However, in this group of 13 patients there were 3 observations in which therapy was started rather late after the onset of the exacerbation. In all 3 cases anti-DNA levels were already decreasing when therapy was being given, and in none of the 3 cases was a clear effect seen on the rate of the decrease (Fig. 8). This suggests that the drop in anti-DNA levels is related to the disease process rather than to therapy.

\section{Discussion}

Earlier studies ${ }^{11}{ }^{16}$ have shown that in SLE a better insight into the relationship between anti-dsDNA levels and disease activity was obtained by expressing the amount of anti-dsDNA antibodies in units $/ \mathrm{ml}$. In the present paper we describe a clear-cut relationship between anti-dsDNA profiles and disease activity in patients with SLE. Out of 130 patients studied 13 developed 15 periods with major clinical symptoms of their disease. All observed periods of major symptoms were heralded by a period with an increasing level of anti-dsDNA, whereas, concomitant with the development of major clinical symptoms antidsDNA levels decreased rapidly. Some questions are prompted on the basis of these observations:

(1) Can anti-dsDNA levels be used for prognostic purposes?

(2) Is the drop in anti-dsDNA related to the pathogenesis of the disease?

All 14 periods with an increasing level of antidsDNA, characterised by a doubling time under 10 weeks, developed major symptoms. In 13 cases the doubling time was 6 weeks or less. Although we feel that we have to enlarge the number of such observations, they strongly suggest that once a patient shows such a fast increase in the serum anti-dsDNA level, the patient is bound to develop an exacerbation.

The relationship between an exacerbation (major symptoms) and the drop in anti-dsDNA level is clear. In 14 patients the $T \frac{1}{2}$ of serum anti-dsDNA was less than 2 weeks. In view of the normal $\mathrm{T}_{2}^{\frac{1}{2}}$ of Ig, we might conclude that this decrease is due to complexation of anti-dsDNA to its antigen. This suggests that immunosuppressive therapy cannot be the explanation for this observation. This notion is enforced by the finding in $\mathbf{3}$ patients that the rate of decrease is not clearly influenced by prednisolone therapy. This leaves us with the question whether the complexation of anti-dsDNA is the cause of the exacerbation or the result of it. We do not feel that the present study allows us to draw conclusions on this part.

Although others have published similar results as ours, most investigators claim that anti-dsDNA levels are not very well correlated with disease activity. ${ }^{7-9}$ The reasons for this discrepancy are probably the following. (a) Our method of measuring anti-dsDNA (using circular dsDNA and no incubation at $4^{\circ} \mathrm{C}$ ) selects for high-avidity antibodies. ${ }^{17}$ (b) Our data could be obtained only by titrating the sera, which is not done by most investigators. (c) The pattern of anti-dsDNA levels requires very frequent serum sampling. With this in mind we feel that most of the published data fit in our concept.

Although the selection of our patients was probably biased in terms of positivity in the Farr assay and in terms of renal involvement, it is remarkable that none of the 130 patients underwent a major exacerbation without a changing level of anti-dsDNA. It must be realised, however, that absolute values of anti-dsDNA varied from patient to patient.

It is also clear that a number of patients show a more or less constant high level of anti-dsDNA for years without showing major signs of disease. Why they do not develop an exacerbation remains speculative.

The conclusion of this study is that, when SLE patients are monitored frequently for anti-dsDNA, exacerbations can be foreseen. As a consequence it is possible that immunosuppressive therapy can be guided by the anti-dsDNA levels. When this therapy is started in the phase of increasing anti-dsDNA levels, we might be able to normalise anti-dsDNA before the exacerbation takes place. Another conclusion from our work must be that an isolated determination of anti-dsDNA can be used for diagnostic purposes $^{11}$ but not as a measure of disease activity. For this purpose frequent serum sampling is necessary.

The study was financially supported by the Netherlands League against Rheumatism. 


\section{References}

1 Aarden L A, Lakmaker F, de Groot E R, Swaak A J G, Feltkamp T E W. Detection of antibodies to DNA by radioimmunoassay and immunofluorescence. Scand J Rheumatol 1975; suppl 11: 12-9.

2 Pincus T, Shur P H, Rose J A, Decker J L, Talal N. Measurement of serum DNA binding activity in lupus erythematosus. $N$ Engl $J$ Med 1969; 281: 701-5.

${ }^{3}$ Davis P, Hughes G R V. Antibodies in discoid lupus erythematosus. Br J Dermatol 1974; 91: 175-81.

4 Hughes G R V. Frequency of anti-dsDNA antibodies in SLE, RA and other diseases. Scand J Rheumatol 1975; suppl 11: 42-51.

5 Rochmis PG, Palefsky H, Becker M, Roth M, Zvaifler N J. Native DNA binding in rheumatoid arthritis. Ann Rheum Dis 1974; 33: 357-60.

- Hasselbacher P, Leroy E C. Serum DNA binding activity in healthy subjects and in rheumatic diseases. Arthritis Rheum 1974; 17: 63-71.

${ }^{7}$ Lightfoot R W, Redecha P B, Levesanos M. Longitudinal studies of anti-DNA antibody levels in SLE. Scand J Rheumatol 1975; suppl 11: 52-8.

${ }^{8}$ Schur P H, Sandson J. Immunological factors and clinical activity in systemic lupus erythematosus. N Engl J Med 1968; 278: 533-8.
- Appel A E, Sabley L B, Golden R A, Barland P, Grayzel A I, Bank $W$. The effect of normalization of serum complement and anti-dsDNA antibody on the course of lupus nephritis. Am J Med 1978; 64: 274-83.

${ }^{10}$ Swaak A J G. Longitudinal studies of anti-dsDNA. Scand $J$ Rheumatol 1975; suppl 11: 57-8.

11 Swaak A J G, Aarden L A, Statius van Eps L W, Feltkamp T E W. Anti-dsDNA and complement profiles as prognostic and therapeutic guides in systemic lupus erythematosus. Arthritis Rheum 1979; 22: 226-35.

12 Espejo R T, Canelo E S. Properties of bacteriophage $\mathrm{PM}_{2}$ : a lipid containing bacterial virus. Virology 1968; 34: 738-47.

${ }^{13}$ Aarden L A, Lakmaker F, Feltkamp T E W. Immunology of DNA II. The effect of size and structure of the antigen in the Farr assay. J Immunol Methods 1976; 10: 39-48.

14 Aarden L A. Measurement of anti-DNA antibodies. Ann Rheum Dis 1977; suppl 36: 91-5.

${ }^{15}$ Lightfoot R W, Hughes G R V. Significance of persisting serologic abnormalities on SLE. Arthritis Rheum 1976; 19: 837-43.

${ }^{16}$ Aarden L A, Lakmaker F, de Groot E R. Immunology of DNA IV. Quantitative aspects of the Farr assay. J Immunol Methods 1976; 11: 153-63.

${ }^{17}$ Smeenk R, Aarden L A. The use of polyethylene glycol precipitation to detect low-avidity anti-dsDNA antibodies in systemic lupus erythematosus. J Immunol Methods 1980; 39: 165-80. 